\title{
Surfactants for dispersion of carbon nanotubes applied in soil stabilization
}

\author{
Diogo T.R. Figueiredo ${ }^{\mathrm{a}}$, António Alberto S. Correia ${ }^{\mathrm{b}, *}$, David Hunkeler ${ }^{\mathrm{c}}$, \\ Maria Graça B.V. Rasteiro ${ }^{a}$ \\ a CIEPQPF, Chemical Engineering Department, University of Coimbra, Portugal \\ b CIEC, Civil Engineering Department, University of Coimbra, Portugal \\ c AQUAETECH, La Plaine, Switzerland
}

\section{G R A P H I C A L A B S T R A C T}

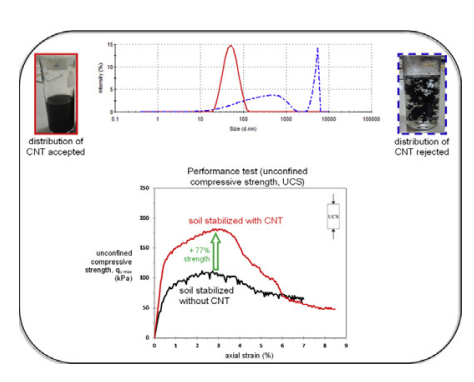

\section{A R T I C L E I N F O}

\section{Article history:}

Received 31 July 2014

Received in revised form

29 November 2014

Accepted 7 December 2014

Available online 31 December 2014

\section{Keywords:}

Carbon nanotubes

Soil stabilization

Particles' dispersion

Dynamic Light Scattering

Surfactants

\begin{abstract}
A B S T R A C T
The discovery of the unique properties of carbon nanotubes (CNT) did grow interest to its application in nanocomposites, for a wide variety of purposes. However, the greatest challenge for its application is associated with the natural tendency to aggregate, resulting in the loss of its beneficial properties. To overcome this problem it is common the use of surfactants and/or ultrasonic energy to promote their dispersion in suspension. This work is focused on the influence of surfactants' properties on the dispersion of carbon nanotubes and on the influence of the quality of the dispersions on the mechanical properties of stabilized soil. Two surfactants (Glycerox and Amber 4001 differing in molecular weight and charge) were fully characterized, followed by the study of which surfactant concentrations were more efficient on the dispersion of the CNTs. The characterization methods were based on light scattering techniques: Dynamic Light Scattering (DLS) for the hydrodynamic diameter and Static Light Scattering (SLS) for the molecular weight. Suspensions of CNTs were prepared in solutions of the aforementioned surfactants, with different concentrations, and further dispersion was promoted using ultra-sounds $(20 \mathrm{kHz}$ during $5 \mathrm{~min}$ ). The dispersions of CNTs in these two surfactants were then fully characterized using again DLS. Finally, the dispersions of carbon nanotubes were added to the main agent responsible for soil stabilization, the binder (Portland cement type I 42.5R), and the mechanical behavior of the new composite material was studied by unconfined compression strength (UCS) tests. The results of the UCS tests led to conclude that the introduction of CNTs in the binder can have huge impact on the mechanical properties of the stabilized soil. Furthermore, the quality of the dispersion of CNTs has got a very high impact on the performance achieved. It was verified an improvement up to $77 \%$ on the compressive strength of the material and $155 \%$ on Young's modulus, referred to the reference test where no carbon nanotubes nor surfactant were added, fundamentally dependent on surfactant type and concentration used.
\end{abstract}

(C) 2014 Elsevier B.V. All rights reserved.

\footnotetext{
* Corresponding author. Tel.: +351239 797277; fax: +351239797123.

E-mail address: aalberto@dec.uc.pt (A.A.S. Correia).
} 


\section{Introduction}

The sudden growth of urban perimeter due to the economic development of modern societies in conjunction with the progressive concentration of the world's population and of industrial complexes on the periphery of major cities, has led to increased occupation of soils with poor geotechnical properties, characterized by low strength and high compressibility. To overcome these difficulties and make possible the construction on such soils, it is common the adoption of reinforcement or stabilization techniques, being the chemical stabilization one of the techniques that have been used with success.

The chemical stabilization of a soil is a technique where the soil is mixed in situ with cementitious materials in order to improve its mechanical behavior. As a result of this mixture there are physicochemical interactions that occur between soil particles, the binders and water present in the soil, resulting in a new composite material with a better mechanical behavior than the original one. This stabilizing effect is a consequence of cementitious bonds between soil particles which promote the formation of a new stronger and stiffer matrix.

The chemical stabilization is dependent on a wide range of parameters, being the most important ones associated to the soil properties (particles size distribution, plasticity characteristics, organic matter content, chemical composition, $\mathrm{pH}$ ) and cementitious materials (type, quantity). The inherent characteristics of the soil are in general impossible to change at the site to tune the chemical stabilization. So, the subsequent study focus on the impact that cementitious materials, in the majority of cases Portland cement $[1,2]$, have on the mechanical behavior of the stabilized soil and on the possibility of replacing part of the Portland cement by additives $[2,3]$ specifically adapted to the soil requirements, resulting in technical and economic advantages. In this exploratory work it is studied a nanoparticle-based additive, more precisely carbon nanotubes (CNTs).

Carbon nanotubes (CNTs) are particularly attractive for use in cementitious systems because they are ideal reinforcing materials. Their unique physical properties, including ultrahigh specific surface, extremely high yield strength and moduli of elasticity, and elastic behavior all point to the potential of CNTs in reinforcing applications [4]. In addition, the introduction of nanoparticles, which have a fine structure on the order of a few nanometers [5], in the cementitious material, has the potential to affect both the physical structure and the chemical reactions occurring during cement curing. The greatest challenge for the application of carbon nanotubes as an additive in soil stabilization is associated with its natural tendency to aggregate, resulting in the loss of its beneficial properties. To overcome this problem it is common the use of surfactants (anphiphilic polymers) and/or ultrasonic energy to promote dispersion of carbon nanotubes in suspension. The use of ultrasounds should be minimized because it is an energy-inefficient technique, thus the use of surfactants can help in minimizing ultrasounds requirement.

Most research work to date has been done with carbon nanotubes added to cement pastes and concretes [4,6-9] neglecting the study with soil matrixes. The carbon nanotubes are not a cementitious material but once introduced in a soil they are expected to reduce the interparticles' spacing, which will promote the construction of a stronger and stiffer soil skeleton matrix, together with the cementitious materials, therefore improving the mechanical properties of the soil. Thus, optimization of nanoparticles distribution is required (solving problems related with particle agglomeration) to obtain a final material with the best characteristics at a competitive cost.

This work is focused on the application of carbon nanotubes (more precisely, multiwall carbon nanotubes, MWCNTs) on soil stabilization, evaluating its applicability in terms of the quality of the dispersion of the suspension and of the mechanical behavior of the new composite material. Two surfactants (Glycerox and Amber 4001 - different molecular weight and charge) were chosen for this purpose. The choice was to evaluate the influence of molecular weight and charge on the quality of the dispersion. The two surfactants were fully characterized before being used to disperse the CNTs. Then, the characterization of the dispersions of CNTs in these surfactants solutions was performed. The characterization relied on light scattering techniques, including Dynamic and Static Light Scattering and Electrophoretic Light Scattering. Finally, the dispersions of carbon nanotubes were added to the main agent responsible for soil stabilization, the Portland cement, and the mechanical behavior of the stabilized soil was studied by unconfined compressive strength (UCS) tests.

\section{Materials and experimental procedure}

\subsection{Materials}

The present work is based on a Portuguese soft soil, taken from a location in the center of Portugal (region known as Baixo Mondego). In general, the soil is mostly composed of silt ( $2 \mu \mathrm{m}<$ size < $0.6 \mathrm{~mm}$ : 66\%) with some clay (size $<2 \mu \mathrm{m}$ : $12 \%$ ) and sand $(0.6 \mathrm{~mm}<$ size $<2 \mathrm{~mm}$ : $22 \%$ ) particles, with a high organic matter content $(9.3 \% \mathrm{w} / \mathrm{w})$, which has a strong influence on some characteristics of the soil, namely, low unit weight $\left(\gamma=14.6 \mathrm{kN} / \mathrm{m}^{3}\right)$, high plasticity, high natural water content $\left(w_{\text {nat }}=80.9 \% \mathrm{w} / \mathrm{w}\right)$, high void ratio, low strength and high compressibility. Moreover, the soil exhibits a specific gravity of 2.555 and a porosity of $67.8 \%$.

The analysis of the mineralogical and chemical composition of the soft soil (Table 1 ) reveals a high content of silica $\left(\mathrm{SiO}_{2}\right)$ and alumina $\left(\mathrm{Al}_{2} \mathrm{O}_{3}\right)$, which combined with its fineness confers pozzolanic properties to the soil. Therefore, in the long term it can react with calcium hydroxide producing strength-enhancing reaction products $[5,10]$. The soil exhibits a reduced value of $\mathrm{pH}$, which can restrain and/or delay some reactions during the chemical stabilization $[2,3,11]$. A more detailed description and characterization of the soil can be found in [11-13].

The soil studied was collected at a depth of $2.5 \mathrm{~m}$ and was homogenized in laboratory in order to control variations in the main characteristics of the soil, making it easy to have representative samples of the soil in its natural conditions. Once homogenized, the necessary soil for the accomplishment of this work was packaged in a thermo-hygrometric chamber at a temperature of $20 \pm 2{ }^{\circ} \mathrm{C}$ and a relative humidity of $95 \pm 5 \%$ until the date of use.

The binder selected to chemically stabilize the soil was a Portland cement type I, class of mechanical resistance 42.5 (CEM I $42.5 \mathrm{R})$, with a chemical composition in terms of the main constituents given in Table 2. The cement particles have a specific surface of $349.0 \mathrm{~m}^{2} / \mathrm{kg}$ and are negatively charged (zeta potential measured using electrophoretic light scattering - Zetasizer NanoZS from Malvern Inst., UK, was $-2.14 \mathrm{mV}$, which is in accordance with [14]). The amount of Portland cement used for the chemical stabilization of the soil was 175 kilos per cubic meter of soil.

For this exploratory study, it was decided to use MWCNTs mainly due to cost $(100 € / \mathrm{kg})$ which is significantly lower than the single-wall carbon nanotubes (SWCNTs). MWCNTs were supplied by Nanocyl and, according to producer data, the MWCNT CN7000 have an average diameter of $9.5 \mathrm{~nm}$, average length of $1500 \mathrm{~nm}$ and a specific surface between 250,000 and $300,000 \mathrm{~m}^{2} / \mathrm{kg}$ (about 1000 times higher than cement particles). MWCNTs are composed essentially of pure carbon (90\%), with some metal oxides (10\%). Further characterization of the MWCNTs was conducted with the 
Table 1

Mineralogical and chemical composition of the soft soil.

\begin{tabular}{|c|c|c|c|c|c|c|}
\hline \multicolumn{7}{|c|}{ Mineralogical composition (X-ray diffraction analysis) } \\
\hline Quartz & Feldspar K+ Muscovite & Vermiculite & Ilite & Kaolinite & Chlorite Fe & \\
\hline$>60-65 \%$ & $<25-30 \%$ & $4.6 \%$ & $2.4 \%$ & $1.5 \%$ & $1.5 \%$ & \\
\hline \multicolumn{7}{|c|}{ Chemical composition (weight percentages) } \\
\hline $\mathrm{CaO}(\%)$ & $\mathrm{SiO}_{2}(\%)$ & $\mathrm{Al}_{2} \mathrm{O}_{3}(\%)$ & $\mathrm{Fe}_{2} \mathrm{O}_{3}(\%)$ & $\mathrm{MgO}(\%)$ & $\mathrm{K}_{2} \mathrm{O}(\%)$ & $\mathrm{pH}(-)$ \\
\hline 0.74 & 62 & 16 & 4.8 & 1.1 & 3 & 3.5 \\
\hline
\end{tabular}

assessment of the mass density $\left(1.7 \mathrm{~g} / \mathrm{cm}^{3}\right)$ and zeta potential $(-25.2 \mathrm{mV}$, evaluated by electrophoretic light scattering - Zetasizer NanoZS, Malvern Inst., UK).

In this study two surfactants were tested as additives to promote the dispersion of the MWCNTs. The surfactant Amber 4001 was produced, supplied and protected by legal rights by the company AQUATECH from Switzerland. The Glycerox is a commercial surfactant which is produced by the company Lubrizol. Table 3 shows some properties of the surfactants.

\subsection{Experimental procedure}

The experimental procedure adopted is based in two types of tests: size distribution using Dynamic Light Scattering (DLS) to assess the size and molecular weight of the surfactants and the quality (size) of the dispersion of MWCNT on an aqueous medium; and unconfined compressive strength (UCS) tests in order to evaluate the mechanical performance of the soil chemically stabilized with a binder which incorporates MWCNT "properly" dispersed in an aqueous medium, either pure water or a solution of surfactants (with concentrations up to $3 \% \mathrm{w} / \mathrm{w}$ ).

\subsubsection{Hydrodynamic diameter of the surfactants molecules}

In order to determine the molecular diameter for each surfactant, which are originally emulsions, a solution was prepared with $0.5 \%(\mathrm{w} / \mathrm{w})$ of surfactant, which was analyzed in the Zetasizer NanoZS (ZSN) equipment. The procedure of preparation of solutions was the following:

(1) In a beaker, to the required amount of surfactant, water was added in a quantity not exceeding $50 \mathrm{~mL}$ (normally $40 \mathrm{~mL}$ ) and then shacked for two hours, with the help of a magnetic stirrer, in order to promote a better dissolution of surfactant in water, forming the desired solution.

(2) Two hours later the content was moved to a $50 \mathrm{~mL}$ dilution flask and was completed with water. The solution is ready for use.

(3) Samples of the surfactant solution were put in a square glass cell and introduced in the ZSN equipment. Temperature was set to $25^{\circ} \mathrm{C}$ in the chamber.

In order to ensure that the results are reproducible, all tests were performed on the equipment at least twice, and the result adopted corresponds to the arithmetic average of all tests done in the same situation.

Regarding the assessment of the molecular weight of the surfactants, Static Light Scattering (SLS) was used. Surfactant solutions with different concentrations $(0.075-0.8 \% \mathrm{w} / \mathrm{w})$ were prepared, following the procedure described above, and were successively analyzed in the ZSN equipment. Toluene was used as standard. Pre-

Table 2

Chemical composition of the binder.

\begin{tabular}{lllllll}
\hline \multicolumn{7}{l}{ Portland cement type $\mathrm{I} 42.5 \mathrm{R}$ (weight percentages) } \\
\hline $\mathrm{CaO}(\%)$ & $\mathrm{SiO}_{2}(\%)$ & $\mathrm{Al}_{2} \mathrm{O}_{3}(\%)$ & $\mathrm{Fe}_{2} \mathrm{O}_{3}(\%)$ & $\mathrm{MgO}(\%)$ & $\mathrm{SO}_{3}(\%)$ & $\mathrm{Cl}^{-}(\%)$ \\
\hline 62.84 & 19.24 & 4.93 & 3.17 & 2.50 & 3.35 & 0.01 \\
\hline
\end{tabular}

viously, the refractive index of each solution was determined, also at $25^{\circ} \mathrm{C}$, in the refractometer Atago RX-5000D. By plotting refractive index versus concentration we could obtain $d n / d c$ (variation of refractive index with concentration) which was supplied to the SLS test. The correlation coefficient was always above 99\%. From the SLS measurements the Debye plot was produced which supplied information about the average molecular weight of the surfactant [15].

Fig. 1 presents the size distribution by intensity for the two surfactants, while Fig. 2 shows the molecular weight plots (Debye plots) of the surfactants Glycerox and Amber 4001. Table 3 summarizes the surfactants characterization. More details on how ZSN gives information about size and molecular weight can be found in [13].

\subsubsection{Characterization of MWCNT dispersions}

The method tested in this work for the dispersion of MWCNT consists in the addition of the MWCNT to a suspension of surfactant and subsequent application of ultrasonic energy. The parameters studied were the concentration of surfactant (which ranges from $0.5 \%$ to $3 \% \mathrm{w} / \mathrm{w}$ ) and the amount of MWCNT (which may vary between $0.001 \%$ and $0.01 \%$ ). For a similar situation, Casaleiro [12] determined that the optimum value of ultrasounds time is $5 \mathrm{~min}$ (frequency $20 \mathrm{kHz}$ ), so this value has been adopted in the tests of the present work.

In the first stage, three solutions for each surfactant were prepared with different concentrations. The second stage involves the application of ultrasounds to make the most effective dispersion. The last stage corresponds to the assessment of the size distribution for each MWCNT dispersion, knowing that the smaller the particle size, the better the quality of dispersion (lower presence of aggregates).

The procedure followed for the evaluation of the dispersions quality was as follows:

(1) Three solutions were prepared with $0.5 \%, 1 \%$, and $3 \%$ of surfactant ( $150 \mathrm{~mL}$ of solution).

(2) The amount of MWCNT was added, to a $150 \mathrm{~mL}$ beaker with the solutions previously prepared.

(3) The suspension in the beaker (aqueous solution of surfac$\operatorname{tant}+$ MWCNT) was subjected to ultrasounds during $5 \mathrm{~min}$, using a probe-sonicator (Sonics Vibracell 501), with a frequency of $20 \mathrm{kHz}$ and power $500 \mathrm{~W}$. Casaleiro [12] verified that the simple application of ultrasounds increases the temperature of the suspension until $47^{\circ} \mathrm{C}$, promoting undesirable effects in the dispersion of MWCNT. In order to control this temperature rise, an external circuit was set up with coolant water in and out with the permanent addition of crushed ice to guarantee, in this way, that the temperature of the suspension did not exceed $22^{\circ} \mathrm{C}$.

(4) With the help of a pipette, the suspension was put into a glass cell which was introduced in the ZSN equipment, and the particle size measurement was carried out. This step was repeated for all concentrations of surfactant. At least two measurements of each suspension were made. 
Table 3

Summary of surfactants characterization.

\begin{tabular}{|c|c|c|c|c|c|c|}
\hline Surfactant & Charge & Chain type & $D_{z}(\mathrm{~nm})$ & $D_{\mathrm{z}}^{\mathrm{av}}(\mathrm{nm})$ & $\mathrm{MW}(\mathrm{kDa})$ & $\mathrm{MW}^{\mathrm{av}}(\mathrm{kDa})$ \\
\hline Glycerox & Nonionic & Linear & $\begin{array}{l}41.9 \\
42.0\end{array}$ & 41.95 & $\begin{array}{l}4950.0 \\
3580.0\end{array}$ & 4265.00 \\
\hline Amber4001 & Nonionic & Linear & $\begin{array}{l}5.7 \\
5.6\end{array}$ & 5.65 & $\begin{array}{l}58.0 \\
50.5\end{array}$ & 54.25 \\
\hline
\end{tabular}
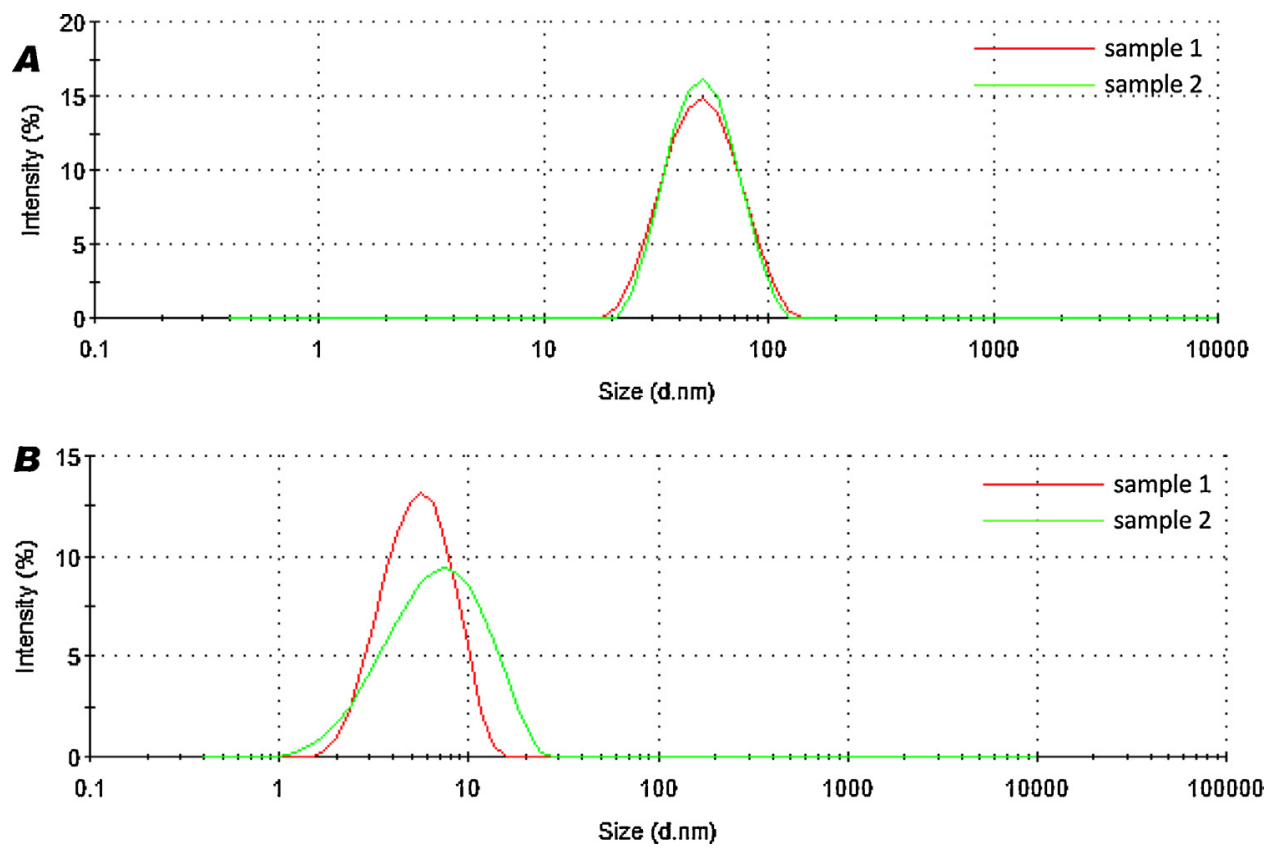

Fig. 1. Size distributions by intensity of the surfactants Glycerox (A) and Amber 4001 (B).

\subsubsection{UCS performance tests}

(1) Homogenization of soil: the soil stored was removed from the thermo-hygrometric chamber and was homogenized manually. The mass required to prepare two samples was taken. The initial water content of the soil was controlled.

(2) Binder preparation: Portland cement was weighed to achieve a concentration of $175 \mathrm{~kg}$ of cement per cubic meter of soil.

(3) Mixing: the cement was blended in a beaker with $150 \mathrm{~mL}$ of suspension (water or aqueous solution of surfactant + MWCNT). Then this mixture was put into the mixing bowl along with soil (the water to binder ratio used was $4.25 \mathrm{w} / \mathrm{w}$ ). It was used a mechanical mixer (Hobart N50) at a rate of $136 \mathrm{rpm}$. The mixture was homogenized during three minutes. After complete mixing, a small portion of the mixture was withdrawn to assess the water content post-blending. The sample must be introduced in the mold straight away up to a maximum time of 30 min after mixing was stopped.

(4) Compression: It was used cylindrical molds made from PVC pipes with inner diameter of $37 \mathrm{~mm}$ and height of $325 \mathrm{~mm}$; in the inner surface of the mold, vaseline was smeared in order to promote the sample slide; at the base of the mold it was glued duct tape and a circular geotextile filter so that the sample does not come out of the mold. The samples were introduced in the mold in six layers. For each layer, a slight compression was applied with a circular plate followed by application of vibration with the help of a hand drill to eliminate air bubbles in the mixture, followed by new slight compression. This process was applied to all six layers. In the end a new circular geotextile filter was applied to the top of the sample.

(5) Curing: the molds with fresh samples were placed in a vertical position on a curing tank filled with water at a temperature of
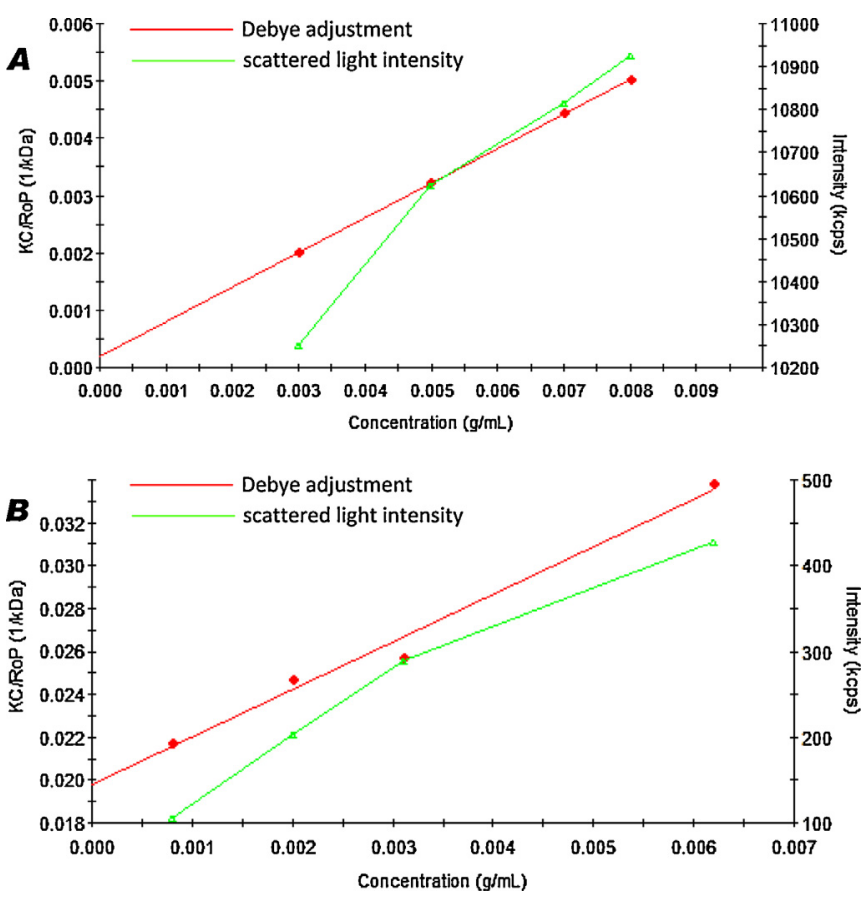

Fig. 2. Debye plot used for molecular weight determination of surfactants Glycerox (A) and Amber 4001 (B). 
Table 4

Tests plan.

\begin{tabular}{|c|c|c|}
\hline Surfactant (-) & Concentration $(\% \mathrm{w} / \mathrm{w})$ & $\operatorname{MWCNT}(\% \mathrm{w} / \mathrm{w})$ \\
\hline \multirow{5}{*}{ Glycerox } & 0.5 & $\begin{array}{l}\overline{-} \\
0.001 \pm 0.0002 \\
0.01 \pm 0.001\end{array}$ \\
\hline & 1 & - \\
\hline & & $\begin{array}{l}0.001 \pm 0.0002 \\
0.01 \pm 0.001\end{array}$ \\
\hline & 2 & - \\
\hline & & $\begin{array}{l}0.001 \pm 0.0002 \\
0.01 \pm 0.001\end{array}$ \\
\hline \multirow{5}{*}{$\begin{array}{l}\text { Amber } \\
4001\end{array}$} & 0.5 & - \\
\hline & & $\begin{array}{l}0.001 \pm 0.0002 \\
0.01 \pm 0.001\end{array}$ \\
\hline & 1 & $\begin{array}{l}- \\
0.001 \pm 0.0002 \\
0.01 \pm 0.001\end{array}$ \\
\hline & 2 & $\begin{array}{l}- \\
0.001 \pm 0.0002 \\
0.01 \pm 0.001\end{array}$ \\
\hline & 3 & $\begin{array}{l}- \\
0.001 \pm 0.0002 \\
0.01 \pm 0.001\end{array}$ \\
\hline
\end{tabular}

$20 \pm 2^{\circ} \mathrm{C}$. During the curing period a vertical pressure of $24 \mathrm{kPa}$ was applied at the top of each sample, in order to simulate actual field vertical effective stress at a depth of $5 \mathrm{~m}$ [11]. The curing time for all samples was 7 days.

(6) Extraction of sample: after 7 days of sample preparation, the sample was ready to be tested. For that the molds were taken from the curing tank and the samples were demolded using a hydraulic extractor. The specimens were carefully cut so that they had a height of $76 \mathrm{~mm}$ and a height/diameter ratio of 2 and weighed after that.

(7) UCS test: the sample is placed on the universal testing machine (Wykeham Farrance - Tristar 5000) and subjected to unconfined compression at a constant deformation rate of $1 \% / \mathrm{min}$ in relation to the height of the sample, which corresponds to $0.76 \mathrm{~mm} / \mathrm{min}$. During the test, the force applied to the sample was automatically registered as a function of the displacement of the sample, using a load cell and a displacement transducer, respectively. After reaching rupture, the sample was removed from the test machine and the final water content was measured.

In order to study and characterize the influence of MWCNT dispersions (with surfactants Glycerox and Amber 4001) on the chemical stabilization of the soft soil under study, a plan of tests that relied on unconfined compressive strength tests (UCS) was defined. The UCS tests aimed to study the behavior of the stabilized soil when subjected to compression efforts in a condition of non-confinement. A reference test where just water was added to Portland cement was made. As surfactants can promote not only the dispersion of MWCNT but also the dispersion of the particles of soil and cement, tests only with surfactant solution were performed as well. Finally, tests with surfactant and MWCNT (applied in different quantities, 0.001 and $0.01 \mathrm{~g}$ ) were performed. The quantity of MWCNT added is defined as the ratio of the weight of MWCNT to the dry weight of cement, here expressed as percentage. Thus, MWCNT concentrations of $0.01 \%$ correspond to $0.01 \mathrm{~g} / 100 \mathrm{~g}$ of Portland cement.

Table 4 presents the tests plan. For each different test conditions, at least two specimens were tested. They were only validated if the range of variation of unconfined compressive strength $\left(q_{\mathrm{u} \text { max }}\right)$ was less than $15 \%$ of the average of the two values of $q_{\mathrm{u} \text { max }}$.
Table 5

Summary of dispersions characterization by DLS.

\begin{tabular}{|c|c|c|c|}
\hline Surfactant (-) & Concentration (\%) & $D_{\mathrm{z}}(\mathrm{nm})$ & $D_{z}{ }^{\text {av }}(\mathrm{nm})$ \\
\hline \multirow{6}{*}{ Glycerox } & \multirow[b]{2}{*}{0.5} & 195.5 & \multirow[t]{2}{*}{197.20} \\
\hline & & 198.9 & \\
\hline & \multirow{2}{*}{1} & 165.4 & \multirow[t]{2}{*}{167.60} \\
\hline & & 169.8 & \\
\hline & \multirow{2}{*}{3} & 184.2 & \multirow[t]{2}{*}{175.20} \\
\hline & & 166.2 & \\
\hline \multirow{6}{*}{$\begin{array}{l}\text { Amber } \\
4001\end{array}$} & \multirow{2}{*}{0.5} & 531.2 & \multirow[t]{2}{*}{521.45} \\
\hline & & 511.7 & \\
\hline & \multirow{2}{*}{1} & 322.3 & \multirow[t]{2}{*}{322.85} \\
\hline & & 323.4 & \\
\hline & \multirow{2}{*}{3} & 315.8 & \multirow[t]{2}{*}{316.80} \\
\hline & & 317.8 & \\
\hline
\end{tabular}

\section{Results}

\subsection{Characterization of MWCNT dispersions}

Fig. 3 shows the dispersions for both surfactants, after the application of ultrasonic energy. The results of particle size distributions of MWCNT dispersed in aqueous solutions of Glycerox and Amber 4001 , for concentrations of $0.5 \%, 1 \%$ and $3 \%(\mathrm{w} / \mathrm{w})$ are represented in Fig. 4 while Table 5 summarizes the average diameters $\left(D_{z}\right)$ for each situation. According to Table 5 , the $D_{z}$ of the dispersions in Glycerox decreases between $0.5 \%$ and $1 \%$ but increases for $3 \%$, justified by the presence of larger particles due to aggregation. So, the best concentration must be between $1 \%$ and $3 \%(w / w)$. This fact justifies the adoption of concentrations of Glycerox up to $2 \%$ for the UCS performance tests. The best MWCNT dispersion is obtained for the concentration of $1 \%$ of surfactant, although the differences between the concentration of $1 \%$ and $3 \%$ of surfactant are small. Table 5 also shows that $D_{z}$ decreases with increasing concentration of Amber 4001. However, once again, variation between concentrations of surfactant from $1 \%$ to $3 \%$ is small. In this case, concentrations up to $3 \%(w / w)$ were used in the UCS tests.

\subsection{UCS performance test}

Soft soils have high levels of porosity, caused by the usually large volume of voids between soil particles. The addition of cement to the soil allows the filling of those free spaces establishing bonds with soil particles, building a more resistant solid matrix and increasing the mechanical properties of soil. If cement is enriched with MWCNT, the increase of mechanical properties can be further enhanced due to the excellent mechanical properties of MWCNT, as long as a good dispersion is ensured.

$q_{\mathrm{u} \text { max }}$ is not more than a uniformly distributed force over an area. The maximum force recorded during the test corresponds to the maximum resistance of the compressive sample and gives information about the resistance of the sample. $E_{\mathrm{u} 50}$ is the secant undrained Young's modulus defined at $50 \%$ of the value of $q_{\mathrm{u} \text { max }}$ and gives indication about the stiffness of the sample [16,17].

Fig. 5 presents the evolution of $q_{\mathrm{u} \text { max }}$ with the concentration of Glycerox and Amber 4001 for each concentration of MWCNT $(0.001 \%$ and $0.01 \% \mathrm{w} / \mathrm{w})$. Fig. 6 represents the evolution of Young's modulus defined for $50 \%$ of $q_{\mathrm{u} \text { max }}\left(\mathrm{E}_{\mathrm{u} 50}\right)$ with the concentration of Glycerox and Amber 4001 for the same concentration of MWCNT $(0.001 \%$ and $0.01 \% \mathrm{w} / \mathrm{w})$.

In the case of Glycerox, it was noted that the increase of strength is related with the improvement of the dispersion quality of MWCNTs. The maximum values of $q_{\mathrm{u} \max }$ occur for higher concentrations of MWCNT $(0.01 \%)$ because good dispersions could be achieved for this situation. Thus, it is possible to exploit this high quantity of MWCNT because they are effectively dispersed. 

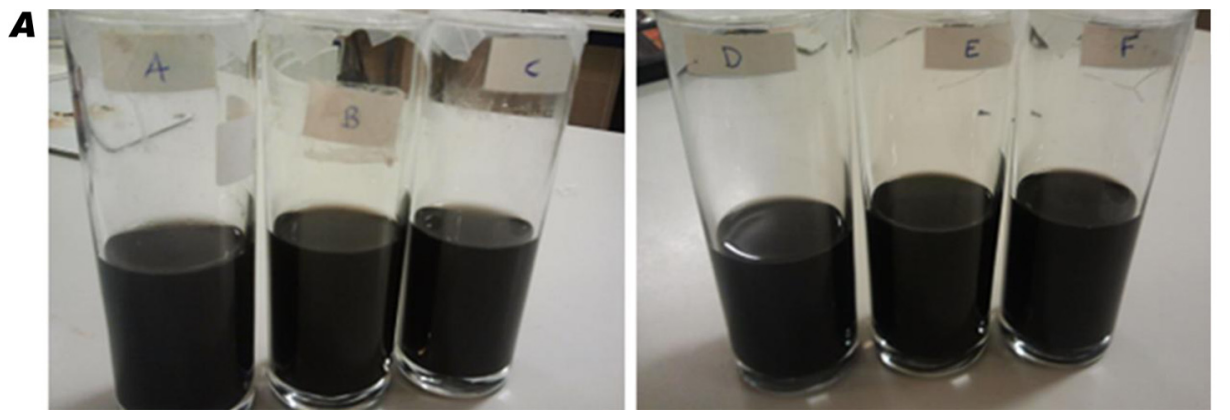

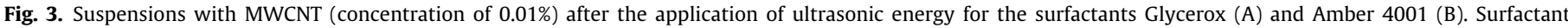
concentration of $0.5 \%, 1 \%$ and $3 \%$ for cups A, B, C and D, E, F, respectively (from left to right).

It was also observed that the addition of this surfactant has a negligible effect on the $\mathrm{E}_{\mathrm{u} 50}$. However, the addition of small quantities of MWCNT $(0.001 \%)$ leads to a huge improvement of $\mathrm{E}_{\mathrm{u} 50}$. For these small quantities of MWCNT (0.001\%), the matrix of cement and soil becomes denser, so the voids are filled by the MWCNT and $\mathrm{E}_{\mathrm{u} 50}$ increases. For the higher concentration of MWCNT, the matrix becomes more dense and resistant (as proved by the $q_{\mathrm{u} \text { max }}$ values), but as in the cement-soil bonding there are potentially more nanoparticles which have high strain at failure, their presence in higher quantities (in series arrangement) induces in the sample a ductile behavior, decreasing the stiffness and thus $\mathrm{E}_{\mathrm{u} 50}$.

In the case of Amber 4001, for concentrations above $1 \%$, the beneficial effect of the addition of MWCNT disappears, even if the dispersion results showed that good dispersion could be obtained (Table 5). One possible explanation is that critical micelle concentration (CMC) may have been exceeded. As a result, there are too many molecules of surfactant, which instead of adsorbing on the surface of the MWCNT to promote their dispersion, may start to form micelles, which in a medium with large particles like soil particles and cement particles can make the reactions between cement and water more difficult decreasing the mechanical performance of the final samples. This is compatible with the good dispersion obtained for a concentration of 3\% of Amber 4001, since the formation of micelles is not necessarily detrimental for particles dispersion. In fact, the same effect is present when only Amber 4001 is mixed with soil and cement. Moreover, for concentrations of $2 \%$ and $3 \%$ of surfactant, samples become more viscous which also contributes to make hydration reactions more difficult. Still, for concentrations of Amber 4001 up to 1\% the improvement in $q_{\mathrm{u} \text { max }}$ is higher than for the case of Glycerox. This may be attributed to the cationic charge of Amber 4001, at low pH, which favors adsorption to the cement particles if concentration is kept below the CMC, in opposition to the nonionic nature of Glycerox.

It was also observed that the addition of Amber 4001 leads to an increase on the $E_{\mathrm{u} 50}$ up to the concentration of $1 \%$ of surfactant. Once again, this suggests that Amber 4001 has a good ability to disperse cement particles until a concentration of surfactant of $1 \%$. Above this concentration there is a negligible increase of $\mathrm{E}_{\mathrm{u} 50}$ for $2 \%$ of surfactant and a decrease for 3\%, comparing with the reference test (zero concentration of surfactant). Regarding the influence of the concentration of MWCNT on $\mathrm{E}_{\mathrm{u} 50}$, the two surfactants behave similar until a concentration of $1 \%$. Above $1 \%$ of surfactant, the effect of the presence of surfactant overlaps the effect of the MWCNT
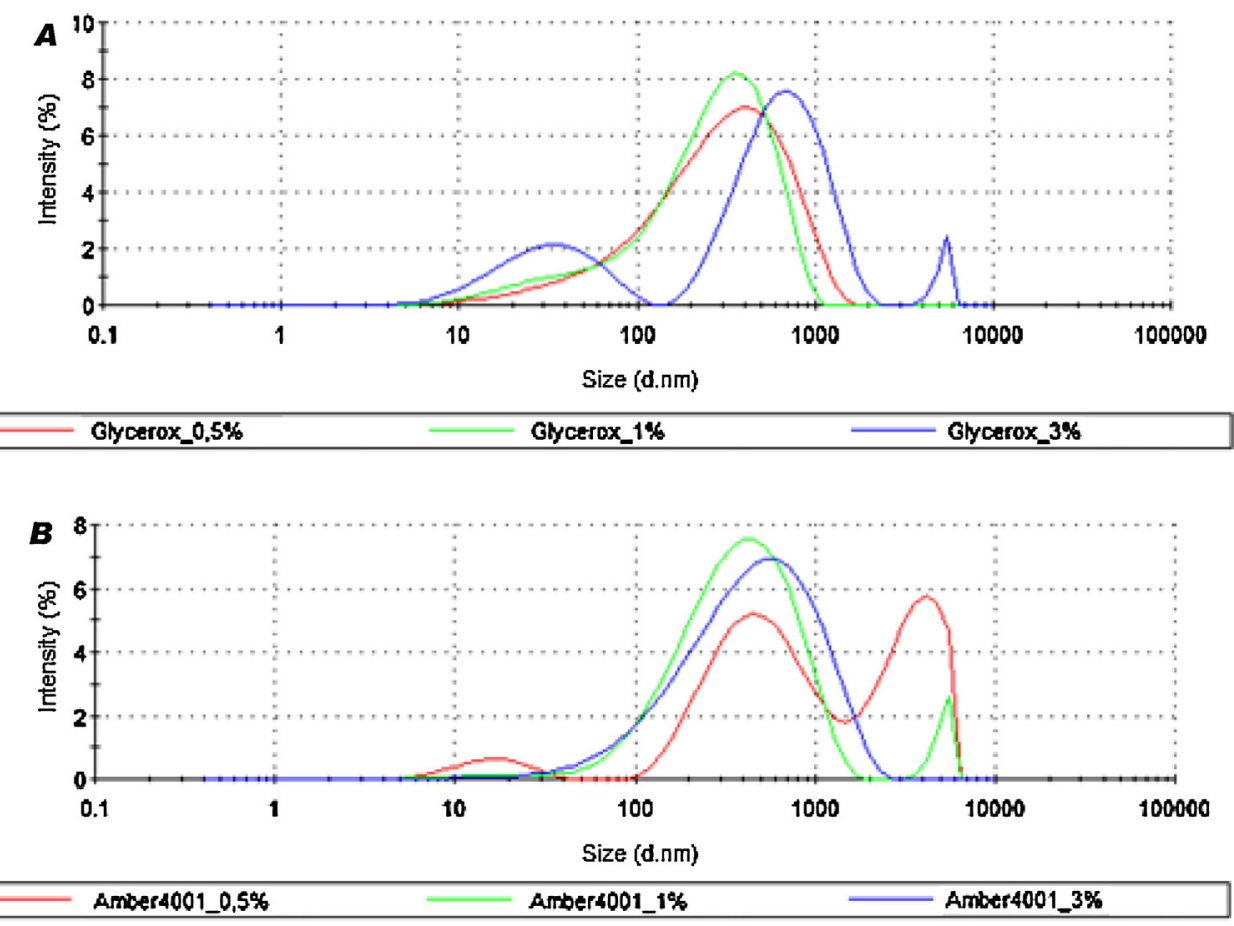

Fig. 4. Size distribution by intensity of suspensions with MWCNT (concentration of $0.01 \%$ ) for the three concentrations tested of Glycerox (A) and Amber 4001 (B). 


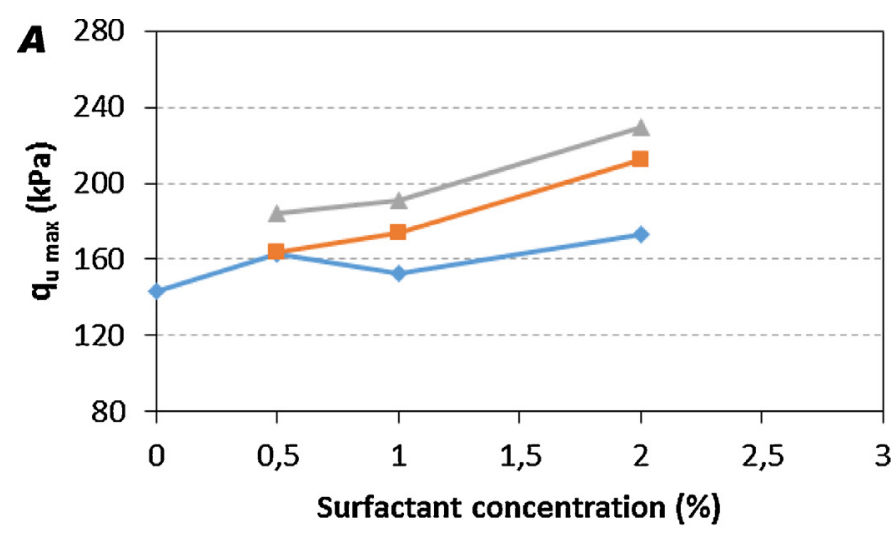

$$
\begin{aligned}
& \text { Curing Time }=7 \text { days } \\
& -\mathrm{MWCNT}=0 \\
& -\mathrm{MWCNT}=0.001 \% \\
& -\mathrm{MWCNT}=0.01 \%
\end{aligned}
$$

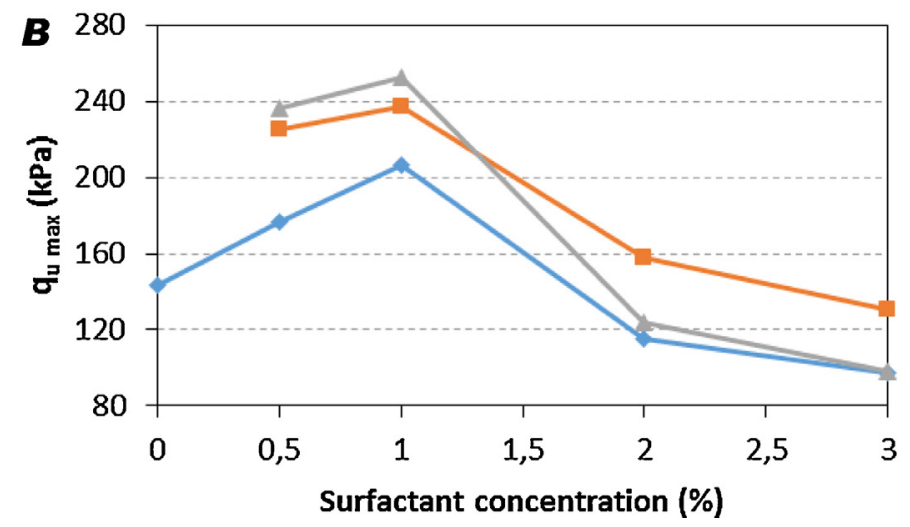

Fig. 5. Evolution of $q_{\mathrm{u} \text { max }}$ with the concentration of Glycerox (A) and Amber 4001 (B) for each concentration of MWCNT.

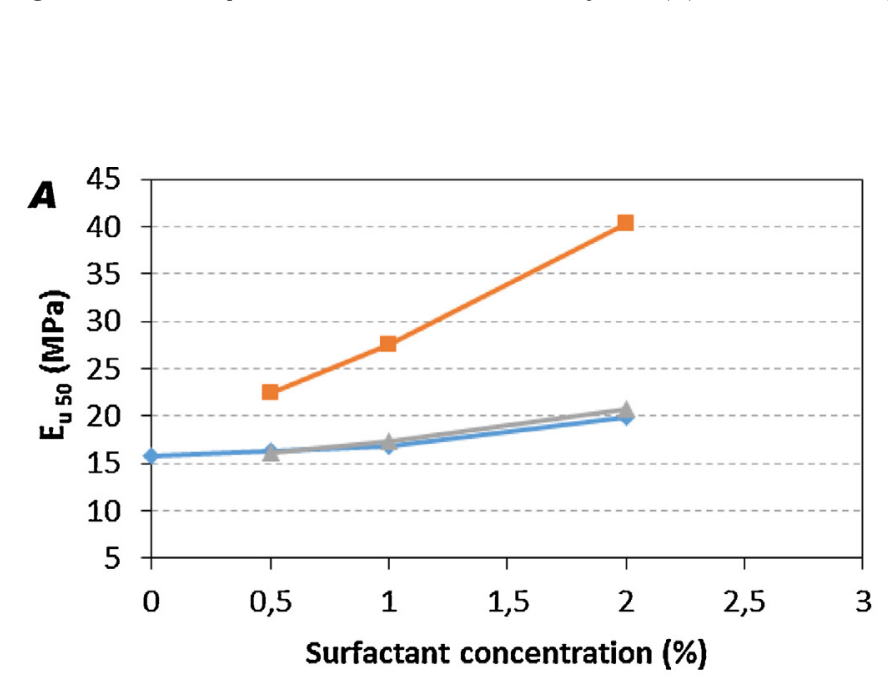

Curing Time $=7$ days

$\multimap \mathrm{MWCNT}=0$

- MWCNTs $=0.001 \%$

$\longrightarrow$ MWCNT $=0.01 \%$

$$
\begin{aligned}
& \text { Curing Time }=7 \text { days } \\
& - \text { MWCNTs }=0 \\
& - \text { MWCNTs }=0,001 \% \\
& - \text { MWCNTs }=0,01 \%
\end{aligned}
$$

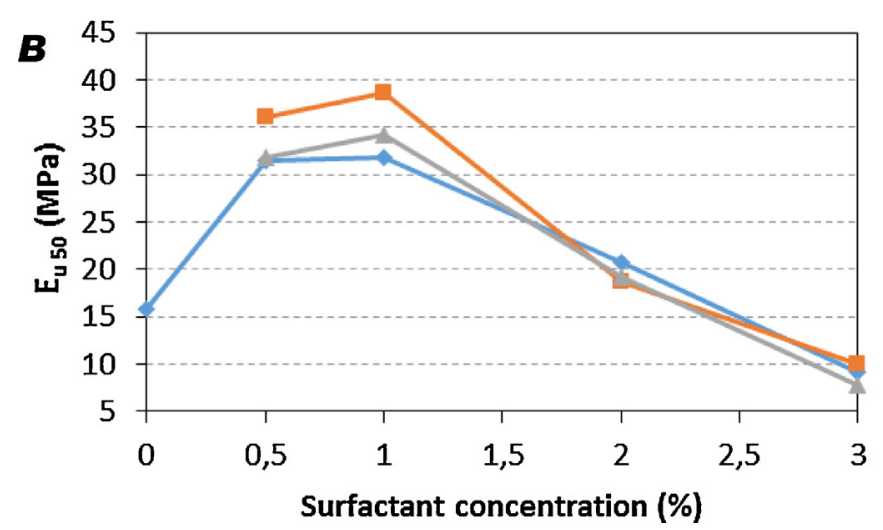

Curing Time $=7$ days

$\longrightarrow$ MWCNTs $=0$

- MWCNTs $=0,001 \%$

- MWCNTs $=0,01 \%$

Fig. 6. Evolution of $\mathrm{E}_{\mathrm{u} 50}$ with the concentration of Glycerox (A) and Amber 4001 (B) for each concentration of MWCNT. 
and $E_{\mathrm{u} 50}$ values seem to be independent of the concentration of MWCNT, for this surfactant (Amber 4001).

In the case of Glycerox and for a concentration of MWCNT of $0.001 \%(w / w)$ there is a continuous increase of $E_{u 50}$ with surfactant concentration, as discussed above. In the case of Amber 4001 the apparent contradiction between the best dispersion achieved for concentrations of 3\% while, in the UCS tests, the best performance is for concentrations of $1 \%$, may also be associated to the differences between the medium where the dispersions occur. The dispersions were evaluated in a medium where MWCNT were mixed only with the aqueous solution of surfactant, while or the UCS tests, these dispersions were placed in a totally different environment where, besides the soil particles (more or less homogenized), there were also cement particles reacting chemically with water.

Another important feature of a surfactant is the ability to disperse the cement particles, as proved by the beneficial effects of adding Amber 4001 to the cement/soil samples. The good dispersion of the cement particles will thus lead to a better filling of "free" spaces between soil particles building a solid matrix even more resistant.

Globally, the most advantageous surfactant is Amber 4001, which besides being the surfactant with overall better results in the UCS tests, with a maximum of $77 \%$ increase in $q_{\mathrm{u} \text { max }}$ and $145 \%$ increase in $E_{\mathrm{u} 50}$ referred to the reference test where no carbon nanotubes nor surfactant were added, is also the surfactant for which a smaller quantity $(1 \% \mathrm{w} / \mathrm{w})$ is necessary to obtain the best results (best compromise of $q_{\mathrm{u} \text { max }}$ and $\mathrm{E}_{\mathrm{u} 50}$ ).

\section{Conclusions}

In this work, cementitious composites reinforced with MWCNT were developed and applied to soft soil to improve its mechanical properties. An amphoteric (Amber 4001) and a nonionic (Glycerox) surfactant were effective to disperse MWCNT. In the case of the non-ionic surfactant (Glycerox) higher hydrodynamic diameter and molecular weight were necessary to obtain adequate dispersion. Based on UCS tests, it was shown that the addition of even a very small quantity of MWCNT, effectively dispersed, improves the mechanical properties of a soil chemically stabilized with cement, this improvement reaching values of the order of $77 \%$ and $155 \%$, respectively for the $q_{\mathrm{u} \text { max }}$ and $\mathrm{E}_{\mathrm{u} 50}$ referred to the reference test where no carbon nanotubes nor surfactant were added. In the case of Amber 4001 (amphoteric surfactant, cationic at low pH) the addition of the surfactant alone, to the cementitious binder, contributed to improve the mechanical properties of the soil as a consequence of the interactions established with the cement particles.

\section{Acknowledgements}

The authors would like to express their thanks to CIMPOR and AQUATECH for supplying the binder and the surfactants, respectively, to Instituto Pedro Nunes that kindly provided the probe-sonicator used and the financial support of FCT through the project PEst/C/EQB/UI0102/2013.

\section{References}

[1] A. Porbaha, State of the art in deep mixing technology: part I. Basic concepts and overview, Gr. Improv. 2 (1998) 81-92.

[2] M. Kitazume, M. Terashi, in: Coastal Development Institute of Technology (Ed.), The Deep Mixing Method - Principle, Design and Construction, Balkema, Japan, 2002.

[3] T.B. Edil, D.A. Staab, Practitioner's guide for deep-mixed stabilization of organic soils and peat. Final Report, The National Deep Mixing Research Program, Project Number NDM302, 2005.

[4] J.M. Makar, The effect of SWCNT and other nanomaterials on cement hydration and reinforcement, in: K. Gopalakrishnan, B. Birgisson, P. Taylor, N.O. AttohOkine (Eds.), Nanotechnology in Civil Infrastructure, Springer, Berlin, Germany, 2011, pp. 103-130.

[5] H.F.W. Taylor, Cement Chemistry, 2nd ed., Thomas Telford, London, 1997.

[6] J.M. Makar, G.W. Chan, Growth of cement hydration products on single-walled carbon nanotubes, J. Am. Ceram. Soc. 92 (6) (2009) 1303-1310.

[7] L. Raki, J. Beaudoin, R. Alizadeh, J. Makar, T. Sato, Cement and concrete nanoscience and nanotechnology, Materials 3 (2010) 918-942.

[8] A. Cwirzen, K. Habermehl-Cwirzen, V. Penttala, Surface decoration of carbon nanotubes and mechanical properties of cement/carbon nanotube composites, Adv. Cem. Res. 20 (2) (2008) 65-73.

[9] M.S. Konsta-Gdoutos, Z.S. Metaxa, S.P. Shah, Highly dispersed carbon nanotube reinforced cement based materials, Cem. Concr. Res. 40 (2010) 1052-1059.

[10] M. Janz, S.E. Johansson, The Function of Different Binding Agents in Deep Stabilization, Swedish Deep Stabilization Research Centre, Report 9, Linköping, Sweden, 2002.

[11] A.A.S. Correia, Applicability of deep mixing technique to the soft soil of Baixo Mondego (Ph.D. dissertation), Univ. of Coimbra, Coimbra, Portugal, 2011 (in Portuguese).

[12] P.D.F. Casaleiro, Chemical stabilization of the soft soil of Baixo Mondego by nanomaterials (M.Sc. thesis), Univ. of Coimbra, Coimbra, Portugal, 2014 (in Portuguese).

[13] D.T.R. Figueiredo, Characterization of carbon nanotubes dispersions for application in soil stabilization (M.Sc. thesis), Univ. of Coimbra, Coimbra, Portugal, 2014.

[14] S. Srinivasan, S.A. Barbhuiya, D. Charan, S.P. Pandey, Characterising cement-superplasticiser interaction using zeta potential measurements, Constr. Build. Mater. 24 (12) (2010) 2517-2521.

[15] C.E. Carraher Jr., Introduction to Polymer Chemistry, 3rd ed., CRC Press, Taylor and Francis Group, Boca Raton, Florida, USA, 2013.

[16] M. Kitazume, M. Terashi, The Deep Mixing Method, CRC Press/Balkema, London, UK, 2013.

[17] T.S. Tan, T.L. Goh, K.Y. Yong, Properties of Singapore marine clays improved by cement mixing, Geotech. Test. J. 25 (4) (2002) 422-433. 